\title{
Tocilizumab inhibits progression of joint damage in rheumatoid arthritis irrespective of its anti- inflammatory effects: disassociation of the link between inflammation and destruction
}

\author{
Josef S Smolen, ${ }^{1,2}$ José C Martinez Avila, ${ }^{1}$ Daniel Aletaha ${ }^{1}$
}

${ }^{1}$ Division of Rheumatology, Department of Medicine 3, Medical University of Vienna, Vienna, Austria

${ }^{2} 2$ nd Department of Medicine, Center of Rheumatic Diseases, Hietzing Hospital, Vienna, Austria

\section{Correspondence to}

Josef S Smolen, Division of Rheumatology, Department of Medicine 3, Medical University of Vienna, Waehringer Guertel 18-20, A-1090 Vienna, Austria; josef.smolen@wienkav.at

Received 8 July 2011 Accepted 25 September 2011 Published Online First 25 November 2011

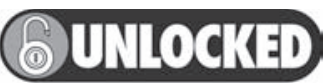

This paper is freely available online under the BMJ Journals unlocked scheme, see http:// ard.bmj.com/info/unlocked.dtl

\begin{abstract}
Background Treatment with tumour necrosis factor inhibitors (TNF-i) plus methotrexate (MTX), but not MTX monotherapy alone, inhibits joint damage progression even at higher levels of disease activity. Such disassociation of disease activity and structural damage has not been shown for biological agents other than TNF-i.
\end{abstract}

Objectives To evaluate whether interleukin 6 (IL-6) inhibition with tocilizumab (TCZ) interferes with joint destruction beyond its effects on disease activity.

Methods A random 90\% sample of data from the (The Tocilizumab Safety and the Prevention of Structural Joint Damage Study) LITHE trial on active rheumatoid arthritis (RA) despite MTX was used, which compared addition of placebo $(n=117)$ with addition of TCZ $(n=414)$ every 4 weeks. Baseline and 1-year values of clinical and serological variables were correlated with changes to 1 year of the total Genant-modified Sharp score (TGSS) using a Spearman test, and the progression of TGSS, erosion and joint space narrowing (JSN) scores in groups with low and high disease activity were compared for placebo and TCZ (Kruskal-Wallis).

Results Baseline variables were similar among the groups. Change of TGSS was lower in patients receiving TCZ than placebo (TCZ: $0.29 \pm 0.96$; placebo: $0.90 \pm 1.92 ; p=0.0007)$. In patients receiving placebo, the correlation with TGSS change was significant for baseline scores of the simplified disease activity index (SDAl; $r=0.18, p=0.047$ ) and swollen joint count 28 $(r=0.22, p=0.019)$, with similar trends for C-reactive protein. Similar correlations were seen for SDAI, clinical disease activity index, disease activity score 28 at 1 year with $x$-ray change during that year $(r=0.26-0.28$, $p=0.002-0.006)$. In contrast, none of the baseline or 1-year variables showed significant correlation with x-ray changes in patients receiving TCZ + MTX, suggesting a disassociation of the link between disease activity and damage by TCZ. Finally, for patients in remission or with low disease activity, progression of TGSS, erosion and JSN was similar among treatment groups (TGSS: placebo, $0.4 \pm 1.1$; TCZ, $0.2 \pm 0.7$; $\mathrm{p}=\mathrm{NS}$ ), while for patients with moderate or high disease activity placebo-treated patients progression was significantly greater (TGSS: $1.2 \pm 2.2$ vs $0.4 \pm 1.2$; $p=0.0009$ )

Conclusions IL-6 inhibition with TCZ plus MTX retards joint damage progression independently of its impact on disease activity. Similar effects have hitherto been reported only for TNF-i. This indicates that the effects of IL-6 inhibition on progression of joint damage in RA are among the most profound currently attainable.

\section{INTRODUCTION}

It is well established that the extent and progression of joint damage in rheumatoid arthritis (RA) is primarily related to the degree of the inflammatory process as depicted especially by joint swelling and the acute phase response, and also by levels of composite measures of disease activity. ${ }^{1-6}$ The correlation between inflammation and joint destruction has been recently even further accentuated by the observation that progression of damage occurs mostly in joints which are swollen and that joint swelling may contribute more strongly to progression of destruction than the acute phase response. ${ }^{78}$ All these relationships concern both the natural course of RA and patients treated with synthetic disease-modifying agents. Therefore, the observation made several years ago that tumour necrosis factor (TNF)-inhibitors in combination with methotrexate (MTX) can halt progression of radiographic joint destruction even in patients who continue to have active disease was somewhat surprising. ${ }^{6-11}$ However, hitherto similar observations have not been made with other biological agents.

While TNF is a pivotal cytokine in RA, ${ }^{12}$ other cytokines, such as interleukin (IL)- 6 also appear to be importantly involved in the pathogenesis of the disease. ${ }^{13}$ Indeed, IL- 6 activates a whole cascade of events characteristic of inflammation, and leads to metalloproteinase-mediated degradation of cartilage matrix and activation of osteoclasts. ${ }^{14-17}$ Tocilizumab (TCZ), an anti-IL-6-receptor antibody, was recently shown to be efficacious in the treatment of RA. Its efficacy includes reduction in signs and symptoms, improvement of physical function and inhibition of joint damage progression. ${ }^{18-21}$ However, it is not known if the effect of TCZ on joint damage is directly related to the reduction of signs and symptoms of inflammatory disease activity or if, similarly to the aforementioned observations on TNF-inhibitors, IL- 6 blockade can interfere with joint destruction beyond its effect on synovitis. Examining this question is the focus of this study. 


\section{PATIENTS AND METHODS}

\section{Datasets}

We were kindly provided by the trial sponsor a $90 \%$ random sample of patient level data from the LITHE clinical trial on patients with active RA despite MTX treatment, ${ }^{21}$ in which signs and symptoms as well as $\mathrm{x}$-ray findings were evaluated.

The data included the traditional clinical variables, such as swollen and tender joint counts (SJC, TJC), patient's and physician's global assessments and patient's pain assessments, acute phase reactant (APR) levels, and the Health Assessment Questionnaire disability index (HAO). Radiographs had been assessed at baseline and 1 year using the total Genant-modified Sharp score (TGSS) 22 by two independent readers blinded to treatment assignment, chronological order of radiographs and patients' clinical responses; this method evaluates hands and feet separately for joint space narrowing (JSN) and erosions with a maximal total score of 200 , which is about half as large as the modified Sharp score and somewhat less than half of the van der Heijde modified (vdH-) Sharp score. ${ }^{23}$ Given that the increments in the TGSS are based on steps of 0.5 and $x$-ray findings were assessed by two readers, in line with previous considerations ${ }^{24}$ progression of joint damage may be regarded as an average score of $\geq 0.25$.

For correlations with joint involvement, we used both the $66 / 68$ and 28-joint counts. We also calculated the disease activity score employing 28 joint count (DAS28) and erythrocyte sedimentation rate (ESR), the simplified and clinical disease activity indices (SDAI, CDAI) as well as disease activity states, remission, low, moderate and high disease activity (LDA, MDA, HDA) using the respective established formulae and cut-off points. ${ }^{25}$

We excluded from further assessment all patients with incomplete data needed for these analyses, which required the availability of clinical and radiographic data at baseline and 12 months; a total of 531 patients fulfilled these criteria. These patients had randomly received placebo $(\mathrm{n}=117), \mathrm{TCZ}$ at $4 \mathrm{mg} / \mathrm{kg}(\mathrm{n}=197)$, or TCZ at $8 \mathrm{mg} / \mathrm{kg}(\mathrm{n}=217)$ every 4 weeks in addition to their insufficiently effective MTX. Importantly, there was no significant difference in clinical variables between patients who had complete datasets and those whose data were incomplete; for example, in the overall population among those who were selected compared with those having missing datasets, the mean swollen joint counts 28 (SJC28) were 12.0 versus 12.0, TJC28 were 15.3 versus 15.8, mean DAS28 was 6.5 versus 6.6, mean CDAI 39.5 versus 40.6 and mean $\mathrm{HAQ}$ was 1.5 in both groups, indicating that there was no selection bias.

\section{Analyses}

We assessed progression of radiological damage in the placebo and active treatment arms by calculating the difference between the 1-year and baseline scores (ATGSS). We partly pooled patients of the 4 and $8 \mathrm{mg} / \mathrm{kg}$ treatment arms, since inhibition of joint damage was similar in these two groups and to increase the sample size and thus the statistical power of this post hoc completer analysis. ${ }^{21}$ We correlated the change in joint damage with baseline and 1-year values of the core set variables (see above) and the three composite measures of disease activity. In additional analyses we focused on patients who experienced progression of joint damage ( $\Delta$ TGSS $>0.25)$ in the placebo and active treatment groups and assessed the relationship of the different baseline variables with progress or status using a multivariate logistic regression model.

Based on the SDAI at 1 year, we then dichotomised patients into those who attained remission or LDA and those who remained in $\mathrm{MDA}$ or $\mathrm{HDA}$, and compared the changes in radiographic scores between these two groups. In a sensitivity analysis we compared the progression of joint damage in patients who achieved a normal C-reactive protein (CRP) $(\leq 0.3 \mathrm{mg} / \mathrm{dl})$ at 1 year with those who did not, as well as in patients who achieved an SJC $\leq 1$ with those who did not.

Statistical analyses were done using R software. ${ }^{26}$ Correlations between individual variables and progression of joint damage were assessed using Spearman correlation; differences between groups were evaluated by Kruskal-Wallis test. In addition, a multivariate logistic regression model was applied. $p$ Values $\leq 0.05$ were considered significant in this exploratory set of analyses.

Table 1 Characteristics of patients in the placebo arm and the pooled treatment arms of tocilizumab, at baseline and after 1 year (mean $\pm S D$, unless indicated otherwise)

\begin{tabular}{|c|c|c|c|c|}
\hline \multirow[b]{2}{*}{ Characteristics } & \multicolumn{2}{|l|}{ Baseline (BL) } & \multicolumn{2}{|l|}{1 Year } \\
\hline & BL PL & BL TCZ & 1-yr PL & 1-yr TCZ \\
\hline $\mathrm{N}$ & 117 & 414 & 117 & 414 \\
\hline Age (years) & $50.3 \pm 12.3$ & $52.5 \pm 11.5$ & - & - \\
\hline Disease duration (years) & $8.57 \pm 8.5$ & $8.85 \pm 7.8$ & - & - \\
\hline Rheumatoid factor (\% positive) & 83.7 & 81.8 & - & - \\
\hline Swollen joint count (0-28) & $11.4 \pm 5.0$ & $12.2 \pm 5.6$ & $4.4 \pm 4.7$ & $3.3 \pm 3.4^{* *}$ \\
\hline Tender joint count (0-28) & $14.2 \pm 6.4$ & $15.5 \pm 6.6^{*}$ & $5.7 \pm 5.7$ & $4.0 \pm 5.2^{* * *}$ \\
\hline Patient global (0-100 mm) & $61.3 \pm 22.0$ & $59.8 \pm 23.3$ & $37.5 \pm 23.2$ & $31.4 \pm 23.5^{* *}$ \\
\hline Evaluator global (0-100 mm) & $59.0 \pm 17.7$ & $62.5 \pm 16.1^{*}$ & $24.4 \pm 17.6$ & $18.8 \pm 16.6^{* *}$ \\
\hline Pain $(0-100 \mathrm{~mm})$ & $52.1 \pm 21.6$ & $53.2 \pm 22.7$ & $33.3 \pm 20.5$ & $28.7 \pm 21.9 * *$ \\
\hline C-reactive protein (mg/dl) & $2.0 \pm 2.3$ & $2.3 \pm 2.6$ & $1.4 \pm 1.7$ & $0.5 \pm 1.2^{* * *}$ \\
\hline Erythrocyte sedimentation rate $(\mathrm{mm} / \mathrm{h})$ & $44.4 \pm 23.5$ & $46.4 \pm 24.9$ & $33.8 \pm 22.0$ & $13.5 \pm 15.8^{* * *}$ \\
\hline Disease activity score 28 (DAS28) & $6.3 \pm 0.8$ & $6.5 \pm 0.9^{*}$ & $4.2 \pm 1.3$ & $2.9 \pm 1.4^{* * *}$ \\
\hline Simplified disease activity index (SDAI) & $39.6 \pm 12.0$ & $42.3 \pm 13.2^{*}$ & $17.7 \pm 12.0$ & $12.8 \pm 10.3^{* * *}$ \\
\hline Clinical disease activity index (CDAl) & $37.6 \pm 11.3$ & $40.0 \pm 12.4$ & $16.3 \pm 11.3$ & $12.3 \pm 10.0^{* * *}$ \\
\hline Health Assessment Questionnaire (HAO) & $1.5 \pm 0.6$ & $1.5 \pm 0.6$ & $1.0 \pm 0.6$ & $0.9 \pm 0.6$ \\
\hline Genant-modified total Sharp score (TGSS) & $27.1 \pm 28.3$ & $27.1 \pm 26.5$ & $28.0 \pm 28.5$ & $27.4 \pm 26.7$ \\
\hline Change in TGSS & NA & NA & $0.90 \pm 1.92$ & $0.29 \pm 0.96^{+}$ \\
\hline
\end{tabular}


Table 2 Values (mean \pm SD) of composite disease activity measures (CDAI, SDAI, DAS28) at baseline and 1 year, and progression of total joint damage score (change in TGSS), ERO and JSN in the patients with moderate/high disease activity according to the respective cut-off points at 1 year of treatment. The data are shown separately for placebo and for the combined tocilizumab (TCZ) groups and for the two TCZ doses. Differences were assessed by Kruskal-Wallis test (for median values of $x$-ray changes see text). According to established cut-off points, patients were regarded as in MDA/HDA with CDAI >10, SDAl $>11$, DAS28 $>3.2$

\begin{tabular}{|c|c|c|c|c|c|c|}
\hline & $\begin{array}{l}\text { Placebo } \\
(76 / 117)\end{array}$ & $\begin{array}{l}\text { Tocilizumab } 4 \mathrm{mg} \\
(97 / 197)\end{array}$ & $\begin{array}{l}\text { Tocilizumab } 8 \mathrm{mg} \\
(100 / 217)\end{array}$ & $\begin{array}{l}\text { p Value vs } \\
\text { placebo }\end{array}$ & $\begin{array}{l}\text { Tocilizumab all } \\
(197 / 414)\end{array}$ & $\begin{array}{l}\text { p Value vs } \\
\text { placebo }\end{array}$ \\
\hline \multicolumn{7}{|l|}{ Baseline values } \\
\hline CDAI & $40.5 \pm 10.8$ & $41.72 \pm 12.13$ & $45.42 \pm 12.74$ & 0.0103 & $43.6 \pm 12.6$ & 0.048 \\
\hline SDAI & $42.5 \pm 11.4$ & $44.04 \pm 12.76$ & $48.17 \pm 13.93$ & 0.0105 & $46.1 \pm 13.5$ & 0.04 \\
\hline DAS28 & $6.5 \pm 0.7$ & $6.70 \pm 0.9$ & $6.95 \pm 0.87$ & 0.0023 & $6.8 \pm 0.9$ & 0.008 \\
\hline HAO & $1.61 \pm 0.61$ & $1.56 \pm 0.58$ & $1.64 \pm 0.63$ & 0.566 & $1.60 \pm 0.60$ & 0.78 \\
\hline \multicolumn{7}{|l|}{ 1-Year values } \\
\hline CDAI & $21.7 \pm 10.4$ & $19.34 \pm 9.26$ & $20.96 \pm 9.36$ & 0.12 & $20.2 \pm 9.3$ & 0.19 \\
\hline SDAI & $23.4 \pm 11.2$ & $20.69 \pm 9.40$ & $21.16 \pm 9.36$ & 0.13 & $20.9 \pm 9.3$ & 0.053 \\
\hline DAS28 & $4.9 \pm 1.1$ & $4.22 \pm 1.12$ & $3.64 \pm 1.03$ & $<0.0001$ & $3.9 \pm 1.1$ & $<0.0001$ \\
\hline $\mathrm{HAO}$ & $1.31 \pm 0.63$ & $1.22 \pm 0.59$ & $1.18 \pm 0.63$ & 0.45 & $1.20 \pm 0.61$ & 0.237 \\
\hline Change in TGSS at 1 year & $1.2 \pm 2.2$ & $0.40 \pm 1.10$ & $0.40 \pm 1.20$ & 0.0038 & $0.4 \pm 1.2$ & 0.0009 \\
\hline Change in ERO at 1 year & $0.65 \pm 1.26$ & $0.28 \pm 0.86$ & $0.23 \pm 0.88$ & 0.0247 & $0.25 \pm 0.87$ & 0.00651 \\
\hline Change in JSN at 1 year & $0.53 \pm 1.21$ & $0.12 \pm 0.47$ & $0.17 \pm 0.55$ & 0.0154 & $0.14 \pm 0.51$ & 0.00435 \\
\hline
\end{tabular}

CDAl, clinical disease activity index; DAS28, disease activity score 28; ER0, erosion; HA0, Health Assessment Questionnaire; HDA, high disease activity; JSN, joint space narrowing score; MDA, moderate disease activity; SDAl, simplified disease activity index; TGSS, total Genant-modified Sharp score.

\section{RESULTS}

\section{Outcomes in the different treatment groups}

Demographic and baseline as well as 1-year RA-related data of the patients studied are shown in table 1 . There were slightly higher TJC, evaluator global assessment (EGA), DAS28 and SDAI values for the TCZ group than for placebo, but these differences were small (mostly $<10 \%$ ), in contrast to the 1-year results which showed significant differences between treatment groups for all clinical variables. In line with the published data, ${ }^{21}$ also in the dataset analysed here the change of TGSS score was significantly higher in patients receiving placebo than those treated with TCZ (placebo: $0.90 \pm 1.92$, TCZ: $0.29 \pm 0.96$, $\mathrm{p}=0.0007$ ). It should be noted that the overall change in $\mathrm{x}$-ray score, even in placebo-treated patients, was very low; this is primarily due to the scoring method, since-as discussed above- the TGSS, in contrast to the modified Sharp and van der Heijde modified Sharp score, has a smaller range, 232527 but possibly also due to a trend towards lower progression of joint damage observed over the past decade. ${ }^{28}$ Even when considering only patients who progressed, the mean change in TGSS was relatively low (placebo: $2.6 \pm 2.5$, TCZ: $1.5 \pm 1.5, p=0.012$ ), thus reducing the overall signal for the associative radiographic analyses.

\section{Correlation of characteristics at baseline and 1 year with progression of joint damage}

In the placebo arm, the correlation analysis with progression of TGSS was significant for baseline SDAI $(\mathrm{r}=0.18, \mathrm{p}=0.047)$ and baseline SJC28 ( $r=0.22, p=0.019)$; a similar trend was seen for baseline CRP ( $\mathrm{r}=0.15, \mathrm{p}=0.106)$ and baseline CDAI $(\mathrm{r}=0.174$, $\mathrm{p}=0.061$ ). Using a full joint count did not result in a better correlation for swollen or tender joint counts (not shown). Similar results were also observed when correlating disease activity at 1 year (instead of baseline) with $\mathrm{x}$-ray progression during that year for SDAI, CDAI and DAS28 ( $r=0.26-0.28, \mathrm{p}=0.002$ to $\mathrm{p}=0.006$ ), with individual variables also showing significant associations or at least trends (data not shown in detail). In contrast, in patients treated with TCZ, none of the baseline or 1 year variables showed significant correlation with $\mathrm{x}$-ray progression (for example, at 1 year, CRP: $r=0.08$; SJC28: $r=0.007$; SDAI: $r=0.005$; all $p$ values $N S)$.

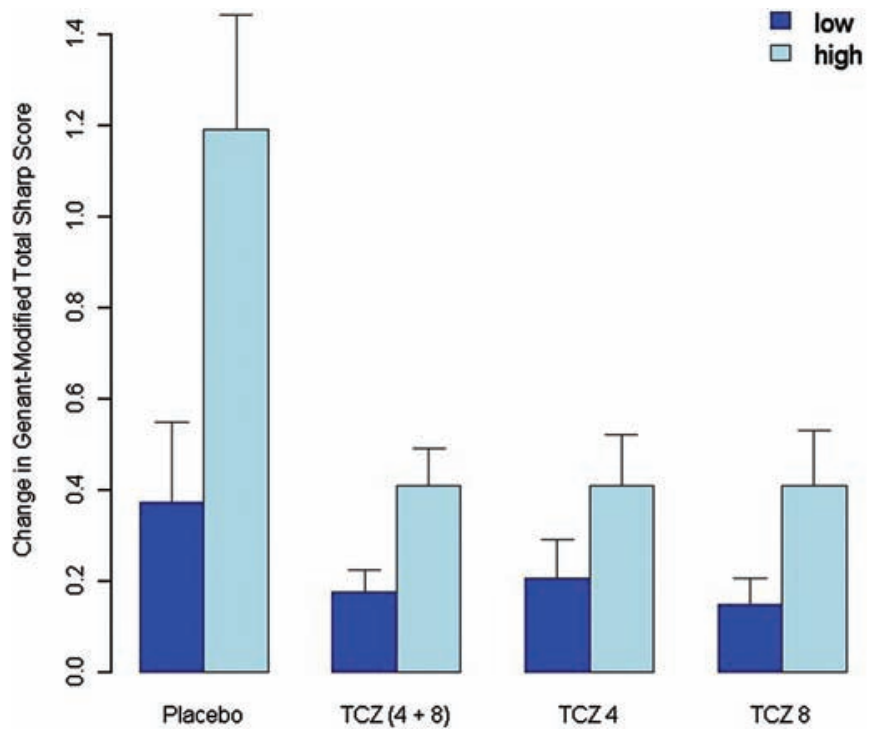

Figure 1 Mean change from baseline to 1 year of the total Genantmodified Sharp score (TGSS) among patients in low disease activity states (low disease activity or remission) and high disease activity states (moderate or high disease activity) after exposure to placebo (plus methotrexate (MTX)), tocilizumab (TCZ) at $4 \mathrm{mg} / \mathrm{kg}$ and/or $8 \mathrm{mg} /$ $\mathrm{kg}$ (plus MTX). The differences in TGSS between low and high disease activity status were significant for placebo $(p=0.0009)$, but generally low and not significant for the TCZ-treated group, irrespective of the dose and disease activity status.

When the area under the curve (AUC) of the predictive variables over 1 year was used instead of their baseline in placebotreated patients, again particularly CRP, SJC28, TJC28, SDAI, CDAI and DAS28 were significantly correlated with radiographic progression $(\mathrm{r}=0.15-0.33)$, confirming the results shown above. In a multivariate logistic model using the AUC of CRP, ESR, SJC and TJC, only CRP was significantly associated with radiographic progression $(p=0.002)$. In line with the lack of significant association in the univariate analyses, the logistic model for patients treated with TCZ did not show any significant results, including for CRP-AUC. 
Table 3 SJC28, CRP and change in TGSS in patients who attained normal CRP (CRP $\leq 0.3 \mathrm{mg} / \mathrm{dl}$ ) at 1 year or not. Data are shown as mean \pm SD for the three treatment arms. $p$ Values denote differences among treatment groups (Kruskal-Wallis test)

\begin{tabular}{|c|c|c|c|c|c|c|c|c|}
\hline \multirow[b]{2}{*}{ Treatment } & \multicolumn{4}{|c|}{$\mathrm{CRP} \leq 0.3 \mathrm{mg} / \mathrm{dl}$} & \multicolumn{4}{|c|}{ CRP $>0.3 \mathrm{mg} / \mathrm{dl}$} \\
\hline & $\mathrm{n}$ & SJC28 & CRP & $\Delta \mathrm{TGSS}$ & $\mathrm{n}$ & SJC28 & CRP & $\Delta \mathrm{TGSS}$ \\
\hline Placebo & 19 & $2.8 \pm 2.9$ & $0.15 \pm 0.08$ & $0.3 \pm 0.6$ & 98 & $4.7 \pm 5.0$ & $1.6 \pm 1.8$ & $1.0 \pm 2.1$ \\
\hline TCZ 4 & 81 & $3.1 \pm 3.8$ & $0.12 \pm 0.09$ & $0.4 \pm 1.2$ & 116 & $3.4 \pm 4.0$ & $1.5 \pm 1.9$ & $0.2 \pm 0.8$ \\
\hline TCZ 8 & 199 & $3.3 \pm 3.9$ & $0.05 \pm 0.05$ & $0.3 \pm 1.0$ & 18 & $3.0 \pm 3.6$ & $1.3 \pm 1.4$ & $0.3 \pm 0.9$ \\
\hline p Value & & 0.979 & 0.0001 & 0.449 & & 0.069 & 0.471 & 0.015 \\
\hline
\end{tabular}

CRP, C-reactive protein; SJC28, swollen joint count 28; TGSS, Genant-modified total Sharp score; TJC28, tender joint count 28, TCZ, tocilkizumab.
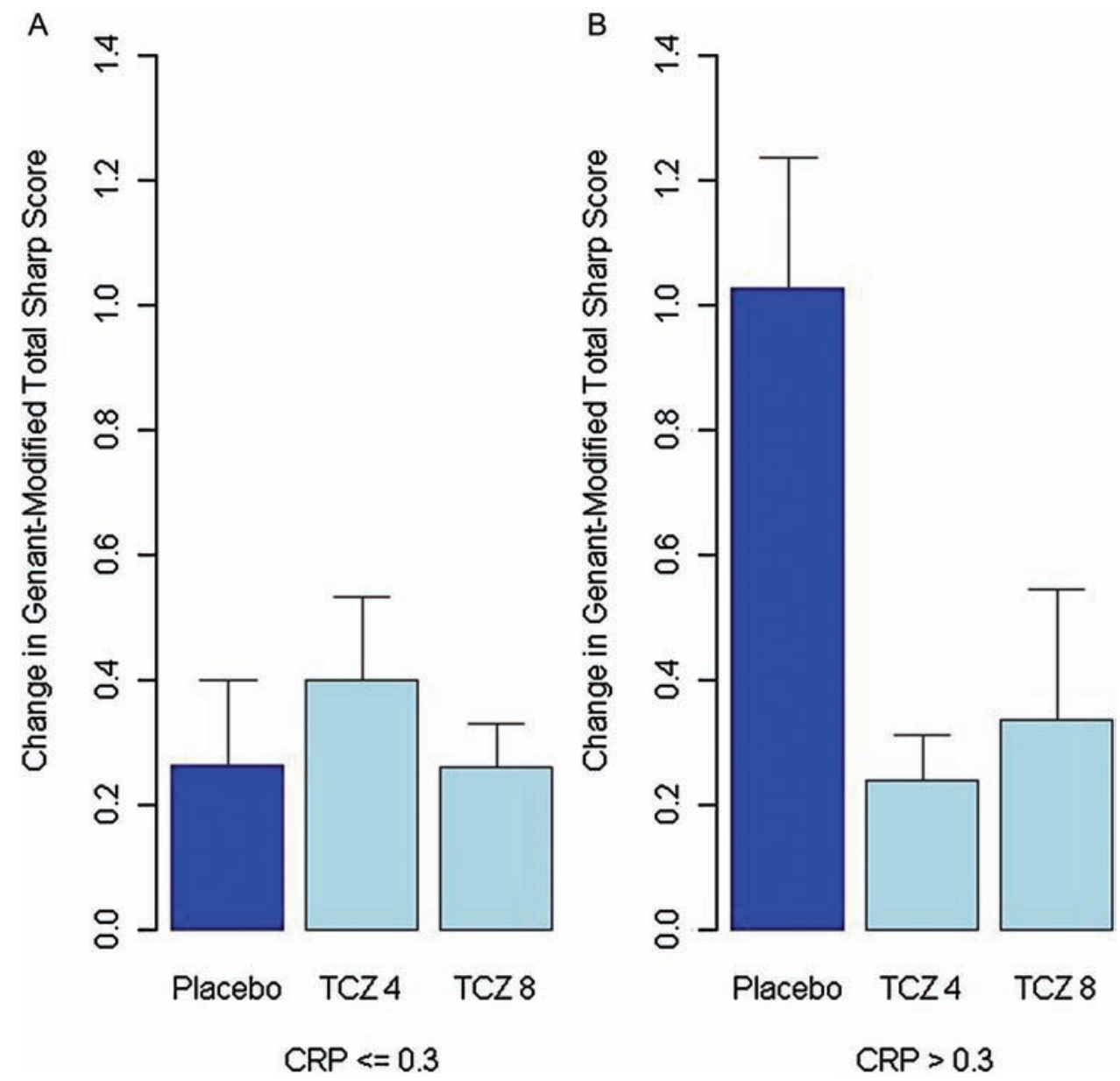

Figure 2 Change from baseline to 1 year of radiographic score in (A) patients with normal C-reactive protein (CRP; $\leq 0.3 \mathrm{mg} / \mathrm{dl})$ at 1 year and (B) patients with raised CRP (>0.3 mg/dl) at 1 year treated with either placebo or tocilizumab (TCZ) at $4 \mathrm{mg} / \mathrm{kg}$ or $8 \mathrm{mg} / \mathrm{kg}$.

Taken together, these data suggested that the link between surrogate markers of disease activity and progression of joint damage could be seen in placebo-treated patients also when the TGSS was employed, but that TCZ treatment abrogates this association between disease activity and destruction, similar to previous reports for TNF inhibitors. 291029

In a further sensitivity analysis, we also tested patients categorised into LDA and HDA by SDAI who had sustained this status for at least the last two consecutive visits. Interestingly, of the 258 patients with LDA at the end point, 206 (80\%) had sustained this state and, likewise, persistent HDA was seen in 221 ( $81 \%$ ) of the 273 patients categorised as having HDA at the end point. Importantly, results similar to the above radiographic data were seen in those patients who had sustained these states (not shown).

\section{Progression of joint damage in high and low disease activity states}

Next, we investigated the subgroups of patients who achieved remission or $\mathrm{LDA}$, or had $\mathrm{MDA} / \mathrm{HDA}$. In the placebo group (with background MTX), 35\% of the patients attained remission or LDA by SDAI at 1 year, while $65 \%$ were in MDA or $\mathrm{HDA}$. Among patients treated with TCZ plus MTX, 52\% attained the lower and $48 \%$ had MDA/HDA after 1 year. The baseline and endpoint scores of composite disease activity (CDAI, SDAI) and functional measures of patients with $\mathrm{MDA} / \mathrm{HDA}$ are shown in table 2 . Given their relative similarity $( \pm 10 \%)$ when comparing placebo with TCZ-treated patients, differences in disease activity are unlikely to explain the observed threefold difference in radiographic progression (mean change 1.2 \pm 2.2 for placebo and $0.4 \pm 1.2$ for TCZ, $p=0.0009$ by Kruskal-Wallis test; figure 1, 
table 2). The finding that DAS28 values at 1 year were highly discordant between the two treatment groups is a consequence of the profound effect of TCZ on the APR, such as ESR, which is overweighted in the DAS28 formula. ${ }^{30} 31$ The APR, CRP, is much less weighted in the SDAI and not included at all in the CDAI and, therefore, the differences between the treatment groups of both indices are much smaller and not significant for patients achieving only MDA/HDA at 1 year; a similar observation was made for the HAQ and likewise when the TCZ group was separated into the 4 and $8 \mathrm{mg} / \mathrm{kg}$ subgroups.

While also among patients attaining remission or LDA, numerically slightly higher progression scores were seen in placebo-treated patients than in those treated with TCZ (means: $0.4 \pm 1.1$ vs $0.2 \pm 0.7$, figure 1 ), these differences were not significant. Importantly, however, in patients receiving placebo the difference in progression of joint damage was significant when comparing those attaining remission or LDA with those achieving MDA or HDA at 1 year $(n=117 ; p=0.011)$, while in the TCZ group this difference was not significant $(n=414 ; p=0.161$, figure 1). Similar data were observed when comparing each of the two TCZ dose groups separately with the placebo group. These data further suggested that TCZ plus MTX interferes with progression of joint damage even in patients who continue to have active disease.

\section{Progression of joint space narrowing and erosions}

The TGSS comprises the erosion and the JSN score. As shown in table 2, the inhibition by TCZ of joint damage progression even in the presence of active disease affected JSN and erosions in a similar way. This finding indicates that TCZ interferes independent of disease activity with both osteoclastogenic and cartilage-degrading pathways. This conclusion is further strengthened by similar findings for the higher and lower TCZ dose (table 2).

\section{Influence of high CRP or high SJC at 1 year}

In a sensitivity analysis, we dichotomised patients in the placebo and TCZ groups into those who had normalised their CRP and those who had not, and assessed progression of joint damage in these patients; in this analysis we evaluated the two tocilizumab groups separately, because it had been established that CRP normalises less frequently at $4 \mathrm{mg} / \mathrm{kg}$ than $8 \mathrm{mg} / \mathrm{kg} .{ }^{1821}$

Among patients with normal CRP at 1 year, the SJCs in those treated with placebo or TCZ were similar (table 3); likewise the progression of joint damage was very similar among all three treatment arms (table 3, figure $2 \mathrm{~A}$ ). The numerically small, but statistically significant difference in CRP levels did therefore not seem to influence progression at this low level.

In contrast, among patients who did not attain normal CRP at 1 year, significantly less progression of joint damage was seen in those receiving TCZ $4 \mathrm{mg} / \mathrm{kg}(0.24 \pm 0.78)$ and $8 \mathrm{mg} / \mathrm{kg}$ TCZ $(0.34 \pm 0.88)$ than in patients receiving placebo $(1.03 \pm 2.07$; $\mathrm{p}=0.015$; figure $2 \mathrm{~B}$ ); mean CRP levels were almost identical in all three groups. However, since the SJC was numerically lower in patients treated with TCZ ( $p=0.07$, Kruskal-Wallis test; table 3) and since progression of joint damage at low disease activity appears to be linked to SJC rather than CRP, 8 we performed an additional analysis looking at patients who did not attain a normal SJC (SJC>1).

Indeed, patients who had SJC $>1$ at 1 year showed significantly less progression of joint damage upon treatment with TCZ $(0.4 \pm 1.2$ in the $4 \mathrm{mg} / \mathrm{kg}$ and $0.3 \pm 1.0$ in the $8 \mathrm{mg} / \mathrm{kg}$ arm) compared with placebo $(0.9 \pm 1.8 ; \mathrm{p}=0.009)$; SJC were quite similar between the treatment groups $(6.3 \pm 4.7,5.5 \pm 3.9$ and $5.5 \pm 3.8$ for the placebo, 4 and $8 \mathrm{mg} / \mathrm{kg}$ groups, $\mathrm{p}=0.578)$.

All these data further support the above observation that TCZ plus MTX reduces progression of, and almost halts, joint damage even in patients who continue to have active disease. This finding is bolstered by revealing similar effects of both TCZ doses studied, despite the fact that the TCZ $4 \mathrm{mg} / \mathrm{kg}$ group had more patients with active disease. ${ }^{21}$

\section{DISCUSSION}

The data presented indicate that TCZ plus MTX removes the usual correlation between disease activity and joint damage. This conclusion is based on the finding that in patients for whom MTX produced an insufficient response, treatment with TCZ led to a significant reduction in the progression of the radiographic score compared with patients receiving placebo, even if these patients had MDA or HDA by composite disease activity score assessment or their CRP or SJC had failed to normalise. Indeed, the progression of joint damage in these patients did not exceed that of patients treated with TCZ plus MTX who attained low disease activity or remission, or whose CRP or SJC had normalised.

Patients in the placebo group had a low progression of the radiographic score only in LDA states, but not at higher disease activity. In contrast, patients treated with TCZ plus MTX had only small changes in joint damage whether they were in LDA or HDA states. Similar findings were obtained with the lower and clinically less effective TCZ dose as with the higher TCZ dose. Moreover, the disassociating effect of TCZ pertained to both bone erosions and cartilage damage, thus affecting the pathogenesis of RA joint destruction in its totality.

The correlation between disease activity and joint damage has hitherto been shown for the Sharp and vdH-Sharp as well as the Larsen score. ${ }^{2} 4532$ Here we have expanded these observations to the Genant-modified Sharp score. This score has no known advantages over the Sharp or vdH-Sharp scores, but it has been validated and used in several recent trials. ${ }^{33-36}$ The scale of the TGSS is smaller than that of the other scores ${ }^{25} 27$ and the progression of joint damage in this study was quite low as a consequence of this fact and/or the observation of reduced progression of joint damage in recently studied patients with RA. ${ }^{28}$ Presumably, owing to the low progression rate, the correlation between individual disease activity measures and TGSS progression was mainly confined to CRP levels. Importantly, however, a similar correlation was seen between progression of joint damage and composite measures. This comprised the CDAI which does not contain an APR, showing that other factors than just APRs contribute to damage, as has been previously shown for other radiographic scores. ${ }^{145}$ Composite scores have the advantage of capturing a larger spectrum of disease activity than single variables, given that their preponderance can vary between, and even within, individual patients. 253738

One of the limitations of our study is that it was a post hoc analysis rather than a prospective study. Therefore, the results from the comparisons of the placebo and TCZ groups, and the association of diseases activity with progression, can only be hypothesis generating. On the other hand, the data had been prospectively obtained, and are in line with previous observations in patients treated with TNF blockers, which all were likewise post hoc assessments. ${ }^{10} 1139$ In this sense, our study expands for the first time the concept to another mode of action-namely, IL6 inhibition. Another limitation is the focus on completers, but having complete data, especially for radiographic outcomes, is a prerequisite of the study and most correlations with joint 
damage observed related to baseline and to 1-year clinical findings; moreover, the selected patients did not differ significantly from those without complete data. The most provoking limitation, though was the small signal observed with the Genantmodified Sharp score. As discussed above, it was satisfying that despite this major limitation within the dataset a correlation between a change in the score and CRP as well as composite measures of disease activity was seen in the control group, as this has been seen for placebo or MTX with other scores. ${ }^{6} 101139$ This correlation was abrogated and progression of joint damage was minimal upon TCZ plus MTX treatment, which together with several sensitivity analyses supports the suggestion of the disassociating effects of IL- 6 pathway inhibition.

IL- 6 activates the cascade of inflammatory events ${ }^{17} 4041$ and directly amplifies osteoclastogenesis, ${ }^{15} 42$ as does TNF. ${ }^{43-46}$ Thus, inhibition of IL- 6 activity as induced by TCZ can impede both cartilage and bony damage, as shown in studies assessing joint destruction or cartilage and bone breakdown products, ${ }^{21} 47$ and interferes with the important link between disease activity (ie, process) and damage (ie, outcome). This has an impact also on clinical non-responders to TCZ, because they will not experience significant progression of joint damage, which is in contrast to patients continuing MTX despite an insufficient response, or to patients receiving de novo MTX who do not attain remission. ${ }^{6} 910$ Nevertheless, the residual disease activity will still affect their physical function and quality of life and, therefore, as for non-responders to other treatments including TNF blockers, these patients will require a change of treatment.

An explanation for the disassociating effect of TNF inhibition has been proposed by hypothesising that activation of osteoclasts may require a higher threshold for TNF effects than the expression of signs and symptoms of inflammation. ${ }^{48}$ The same explanation may be valid for IL-6 blockade, but this will have to be further tested experimentally. Whether a similar effect can be seen with TCZ monotherapy, which also inhibits progression of joint damage, ${ }^{49}$ will have to be studied using respective data. Likewise, to determine whether this effect is specific to IL-6 receptors and TNF inhibition or a more general quality of biological agents, similar studies in rituximab and abatacept databases will have to be performed.

In conclusion, IL-6 receptor inhibition with TCZ, in combination with MTX, entails inhibition of joint damage even in higher disease activity states. This suggests that interference with the IL-6 pathway will achieve the same level of anti-destructive effects as has previously been reported only for several TNF inhibitors.

Acknowledgements The authors thank Roche for providing them with the data for this study. This is a publication from the Joint and Bone Center or Diagnosis, Research and Therapy of Musculoskeletal Disorders of the Medical University of Vienna.

Funding The study was partly supported by a grant from Roche and partly supported through Coordination Theme 1 (Health) of the European Community's FP7; grant agreement number HEALTH-F2-2008-223404 (Masterswitch).

Competing interests JSS and DA received honoraria for consulting and/or speaking engagements from Roche.

Provenance and peer review Not commissioned; externally peer reviewed.

\section{REFERENCES}

1. van Leeuwen MA, van der Heijde DM, van Rijswijk MH, et al. Interrelationship of outcome measures and process variables in early rheumatoid arthritis. A comparison of radiologic damage, physical disability, joint counts, and acute phase reactants. J Rheumatol 1994;21:425-9.

2. Smolen JS, Van Der Heijde DM, St Clair EW, et al. Predictors of joint damage in patients with early rheumatoid arthritis treated with high-dose methotrexate with or without concomitant infliximab: results from the ASPIRE trial. Arthritis Rheum 2006:54:702-10
3. Dawes PT, Fowler PD, Clarke $\mathrm{S}$, et al. Rheumatoid arthritis: treatment which controls the $\mathrm{C}$-reactive protein and erythrocyte sedimentation rate reduces radiological progression. Br J Rheumatol 1986;25:44-9.

4. Aletaha D, Nell VP, Stamm T, et al. Acute phase reactants add little to composite disease activity indices for rheumatoid arthritis: validation of a clinical activity score. Arthritis Res Ther 2005; 7:R796-806.

5. van der Heijde DM, van Riel PL, van Leeuwen MA, et al. Prognostic factors for radiographic damage and physical disability in early rheumatoid arthritis. A prospective follow-up study of 147 patients. Br J Rheumatol 1992;31:519-25.

6. Smolen JS, Han C, van der Heijde DM, et al. Radiographic changes in rheumatoid arthritis patients attaining different disease activity states with methotrexate monotherapy and infliximab plus methotrexate: the impacts of remission and tumour necrosis factor blockade. Ann Rheum Dis 2009;68:823-7.

7. Klarenbeek NB, Güler-Yüksel M, van der Heijde DM, et al. Clinical synovitis in a particular joint is associated with progression of erosions and joint space narrowing in that same joint, but not in patients initially treated with infliximab. Ann Rheum Dis 2010;69:2107-13.

8. Aletaha D, Smolen JS. Rheumatoid arthritis near remission: clinical rather than laboratory inflammation is associated with radiographic progression. Ann Rheum Dis 2011;70:1975-80. Epub 2011 Jul 28.

9. Smolen JS, Han C, Bala M, et al. Evidence of radiographic benefit of treatment with infliximab plus methotrexate in rheumatoid arthritis patients who had no clinical improvement: a detailed subanalysis of data from the anti-tumor necrosis factor trial in rheumatoid arthritis with concomitant therapy study. Arthritis Rheum 2005; 52:1020-30.

10. Landewé R, van der Heijde D, Klareskog L, et al. Disconnect between inflammation and joint destruction after treatment with etanercept plus methotrexate: results from the trial of etanercept and methotrexate with radiographic and patient outcomes. Arthritis Rheum 2006;54:3119-25.

11. Emery $\mathbf{P}$, Genovese MC, van Vollenhoven $\mathrm{R}$, et al. Less radiographic progression with adalimumab plus methotrexate versus methotrexate monotherapy across the spectrum of clinical response in early rheumatoid arthritis. J Rheumatol 2009;36:1429-41.

12. Feldmann M, Maini SR. Role of cytokines in rheumatoid arthritis: an education in pathophysiology and therapeutics. Immunol Rev 2008;223:7-19.

13. Fonseca JE, Santos MJ, Canhão H, et al. Interleukin-6 as a key player in systemic inflammation and joint destruction. Autoimmun Rev 2009;8:538-42.

14. Rose-John S, Scheller J, Elson G, et al. Interleukin-6 biology is coordinated by membrane-bound and soluble receptors: role in inflammation and cancer. J Leukoc Biol 2006;80:227-36.

15. Kotake S, Sato K, Kim KJ, et al. Interleukin-6 and soluble interleukin-6 receptors in the synovial fluids from rheumatoid arthritis patients are responsible for osteoclast-like cell formation. J Bone Miner Res 1996:11:88-95.

16. Kudo 0, Sabokbar A, Pocock A, et al. Interleukin-6 and interleukin-11 support human osteoclast formation by a RANKL-independent mechanism. Bone 2003:32:1-7.

17. Legendre F, Bogdanowicz P, Boumediene K, et al. Role of interleukin 6 (IL-6)/IL-6Rinduced signal tranducers and activators of transcription and mitogen-activated protein kinase/extracellular. J Rheumatol 2005;32:1307-16.

18. Smolen JS, Beaulieu A, Rubbert-Roth A, et al. Effect of interleukin-6 receptor inhibition with tocilizumab in patients with rheumatoid arthritis (OPTION study): a double-blind, placebo-controlled, randomised trial. Lancet 2008;371:987-97

19. Jones G, Sebba A, Gu J, et al. Comparison of tocilizumab monotherapy versus methotrexate monotherapy in patients with moderate to severe rheumatoid arthritis: the AMBITION study. Ann Rheum Dis 2010;69:88-96.

20. Emery $\mathbf{P}$, Keystone E, Tony HP, et al. IL-6 receptor inhibition with tocilizumab improves treatment outcomes in patients with rheumatoid arthritis refractory to anti-tumour necrosis factor biologicals: results from a 24-week multicentre randomised placebo controlled trial. Ann Rheum Dis 2008;67:1516-23.

21. Kremer JM, Blanco R, Brzosko M, et al. Tocilizumab inhibits structural joint damage in rheumatoid arthritis patients with inadequate responses to methotrexate: results from the double-blind treatment phase of a randomized placebo-controlled trial of tocilizumab safety and prevention of structural joint damage at one year. Arthritis Rheum 2011:63:609-21.

22. Genant HK, Jiang Y, Peterfy C, et al. Assessment of rheumatoid arthritis using a modified scoring method on digitized and original radiographs. Arthritis Rheum 1998;41:1583-90.

23. van der Heijde D. How to read radiographs according to the Sharp/van der Heijde method. J Rheumatol 1999;26:743-5.

24. van der Heijde D, Simon L, Smolen J, et al. How to report radiographic data in randomized clinical trials in rheumatoid arthritis: guidelines from a roundtable discussion. Arthritis Rheum 2002;47:215-8.

25. Aletaha D, Smolen JS. The definition and measurement of disease modification in inflammatory rheumatic diseases. Rheum Dis Clin North Am 2006;32:9-44, vii.

26. R Development Core Team. A language and environment for statistical computing R Foundation for Statistical Computing, Vienna, Austria ISBN 3-900051-07-0. http:// www.R-project.org. 2010 (accessed 30 June 2011).

27. Genant HK. Methods of assessing radiographic change in rheumatoid arthritis. Am J Med 1983;75(6A):35-47. 
28. Rahman MU, Buchanan J, Doyle MK, et al. Changes in patient characteristics in anti-tumour necrosis factor clinical trials for rheumatoid arthritis: results of an analysis of the literature over the past 16 years. Ann Rheum Dis 2011:70:1631-40.

29. Vastesaeger $\mathbf{N}, \mathrm{Xu}$ S, Aletaha D, et al. A pilot risk model for the prediction of rapid radiographic progression in rheumatoid arthritis. Rheumatology (Oxford) 2009;48:1114-21.

30. Bakker MF, Jacobs JW, Verstappen SM, et al. Tight control in the treatment of rheumatoid arthritis: efficacy and feasibility. Ann Rheum Dis 2007;66 Suppl 3:iii56-60.

31. Smolen JS, Aletaha D. Interleukin-6 receptor inhibition with tocilizumab and attainment of disease remission in rheumatoid arthritis: the role of acute-phase reactants. Arthritis Rheum 2011;63:43-52.

32. van Leeuwen MA, van Rijswijk MH, Sluiter WJ, et al. Individual relationship between progression of radiological damage and the acute phase response in early rheumatoid arthritis. Towards development of a decision support system. J Rheumatol 1997;24:20-7.

33. Kremer JM, Dougados M, Emery P, et al. Treatment of rheumatoid arthritis with the selective costimulation modulator abatacept: twelve-month results of a phase iib, double-blind, randomized, placebo-controlled trial. Arthritis Rheum 2005; 52:2263-71

34. Cohen SB, Emery P, Greenwald MW, et al. Rituximab for rheumatoid arthritis refractory to anti-tumor necrosis factor therapy: Results of a multicenter, randomized, double-blind, placebo-controlled, phase III trial evaluating primary efficacy and safety at twenty-four weeks. Arthritis Rheum 2006;54:2793-806.

35. Westhovens $\mathbf{R}$, Robles $\mathrm{M}$, Ximenes $\mathrm{AC}$, et al. Clinical efficacy and safety of abatacept in methotrexate-naive patients with early rheumatoid arthritis and poor prognostic factors. Ann Rheum Dis 2009;68:1870-7.

36. Tak PP, Rigby WF, Rubbert-Roth A, et al. Inhibition of joint damage and improved clinical outcomes with rituximab plus methotrexate in early active rheumatoid arthritis: the IMAGE trial. Ann Rheum Dis 2011;70:39-46.

37. van der Heijde DM, van't Hof MA, van Riel PL, et al. Validity of single variables and composite indices for measuring disease activity in rheumatoid arthritis. Ann Rheum Dis 1992;51:177-81.

38. Goldsmith CH, Smythe HA, Helewa A. Interpretation and power of a pooled index. J Rheumatol 1993;20:575-8.
39. Smolen JS, Maini RN, Han C, et al. Radiographic benefit without clinical improvement in infliximab-treated patients with rheumatoid arthritis: reply to comment by Pincus et al. Arthritis Rheum 2005;52:4045-7.

40. Naka T, Nishimoto N, Kishimoto T. The paradigm of IL-6: from basic science to medicine. Arthritis Res 2002;4 Suppl 3:S233-42.

41. Rowan AD, Koshy PJ, Shingleton WD, et al. Synergistic effects of glycoprotein 130 binding cytokines in combination with interleukin-1 on cartilage collagen breakdown. Arthritis Rheum 2001;44:1620-32.

42. Palmqvist $\mathbf{P}$, Persson $\mathrm{E}$, Conaway $\mathrm{HH}$, et al. IL-6, leukemia inhibitory factor, and oncostatin $\mathrm{M}$ stimulate bone resorption and regulate the expression of receptor activator of NF-kappa B ligand, osteoprotegerin, and receptor activator of NF-kappa B in mouse calvariae. J Immunol 2002;169:3353-62.

43. Lam J, Takeshita S, Barker JE, et al. TNF-alpha induces osteoclastogenesis by direct stimulation of macrophages exposed to permissive levels of RANK ligand. J Clin Invest 2000;106:1481-8.

44. Redlich K, Hayer S, Ricci R, et al. Osteoclasts are essential for TNF-alpha-mediated joint destruction. J Clin Invest 2002;110:1419-27.

45. Blüml S, Binder NB, Niederreiter B, et al. Antiinflammatory effects of tumor necrosis factor on hematopoietic cells in a murine model of erosive arthritis. Arthritis Rheum 2010;62:1608-19

46. Kobayashi K, Takahashi N, Jimi E, et al. Tumor necrosis factor alpha stimulates osteoclast differentiation by a mechanism independent of the ODF/RANKL-RANK interaction. J Exp Med 2000;191:275-86.

47. Garnero P, Thompson E, Woodworth T, et al. Rapid and sustained improvement in bone and cartilage turnover markers with the anti-interleukin-6 receptor inhibitor tocilizumab plus methotrexate in rheumatoid arthritis patients with an inadequate response to methotrexate: results from a substudy of the multicenter double-blind, placebo-controlled trial of tocilizumab in inadequate responders to methotrexate alone. Arthritis Rheum 2010;62:33-43.

48. Smolen JS, Aletaha D, Grisar J, et al. The need for prognosticators in rheumatoid arthritis. Biological and clinical markers: where are we now? Arthritis Res Ther 2008;10:208.

49. Nishimoto N, Hashimoto J, Miyasaka N, et al. Study of active controlled monotherapy used for rheumatoid arthritis, an IL-6 inhibitor (SAMURAI): evidence of clinical and radiographic benefit from an $\mathrm{x}$ ray reader-blinded randomised controlled trial of tocilizumab. Ann Rheum Dis 2007;66:1162-7. 